\title{
Os acordos-marco internacionais e as alianças sindicais internacionais: instrumentos de uma necessária transnacionalização da militância sindical
}

MARG-ANTONIN HENNEBERT

\section{Resumo}

Diante da multiplicação atual dos instrumentos de responsabilidade social empresarial (RSE), o dispositivo frequentemente considerado mais avançado em matéria de defesa dos direitos dos trabalhadores consiste na negociação e na assinatura de acordos-marco internacionais (AMIs). Esses acordos, assinados conjuntamente por uma federação sindical internacional e pela direção de uma empresa multinacional, buscam garantir o reconhecimento de certos direitos sociais fundamentais em todas as operações de uma empresa em âmbito internacional. Baseado na análise dos casos de duas empresas norte-americanas que ratificaram AMls, este artigo procura evidenciar a contribuição desse instrumento para a regulação social das multinacionais e esclarecer as condições de sua efetividade, assim como seus limites. Ambos os casos demonstram que a utilidade desses acordos repousa, acima de tudo, no modo como os atores sindicais se apropriam desse instrumento. Por fim, nosso estudo salienta a importância das alianças ou coalizões internacionais entre os representantes sindicais de uma mesma multinacional para acompanhar os acordos e lhes dar um sentido prático em sua realidade local.

Palavras-chave: Direitos dos trabalhadores. Sindicalismo transnacional. Empresas multinacionais. Responsabilidade Social Empresarial.

*HEC Móntreal, Canadá. 


\title{
International framework agreements and international trade union alliances: tools for a necessary transnationalization of trade union militancy
}

\begin{abstract}
In view of the current proliferation of instruments of corporate social responsibility (CSR), the mechanism seen as the most advanced for protecting employees' rights is the negotiation of international framework agreements (IFA). Such agreements, signed between a Global Union Federation and a multinational company, seek to ensure recognition of certain fundamental social rights in all operations of the enterprise at international level. This article analyzes two cases involving North American companies that have ratified such agreements and seeks to highlight the contribution of this instrument to the social regulation of multinational enterprises, but also to shed some light on the conditions for effectiveness of such agreements while stressing their limitations. The two studied cases demonstrate in this respect that the usefulness of IFA rests, above all, on their appropriation by trade union actors. Finally, the study emphasizes the importance for trade union representatives of the same multinational enterprise to join forces in international alliances or coalitions in order to follow up on these agreements and ensure their implementation at the local level.
\end{abstract}

Keywords: Labor rights. Transnational syndicalism. Multinational companies. Corporate Social Responsibility. 


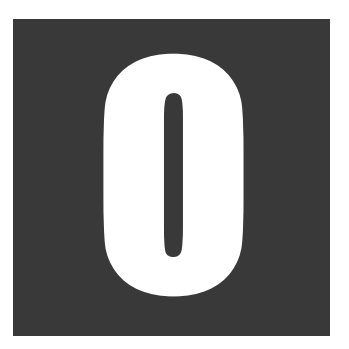

poder cada vez maior das empresas multinacionais e o surgimento das cadeias de abastecimento mundiais modificaram drasticamente o meio das organizações sindicais (Gereffi; Lee, 2016; Milberg; Winkler, 2013). Em vista disso, elevou-se o risco de esses fenômenos conduzirem a um isolamento dos atores sindicais no plano local levando-os a se envolverem em novas formas de microcorporativismo, centradas exclusivamente no aumento do desempenho organizacional das empresas locais (Murray, 2010). Contudo, as pesquisas empíricas realizadas nas últimas décadas sobre essa questão revelam uma realidade mais complexa. Embora tais transformações tenham, às vezes, levado alguns atores sindicais a um retraimento e enfraquecido as forças tradicionais da ação coletiva, outros lançam hoje novas estratégias de reivindicação e investem novos espaços de ação, que instituem formas inéditas de lutas sindicais no plano internacional (McCallum, 2013; Anner, 2012; Hennebert, 2010).

Este artigo não almeja apresentar de modo exaustivo a totalidade das estratégias e dos instrumentos elaborados pelas organizações sindicais nas últimas décadas para tentar se adaptar a essas novas realidades, mas se debruça sobre um instrumento específico, os acordos-marco internacionais (AMIs). Tais acordos visam essencialmente a garantir o respeito aos direitos dos trabalhadores, instaurando mecanismos permanentes de troca de informações e de controle, que apregoam a implantação de práticas sadias de trabalho em todas as operações de uma empresa internacional. São geralmente assinados, por um lado, pela direção da empresa e, no mínimo, por uma Federação Sindical Internacional (FSIs); em alguns casos, participam também outros parceiros sindicais e comitês de empresa europeus (Dehnen, 2013). Embora seu conteúdo possa variar, o denominador comum consiste nas referências a certas convenções da Organização Internacional do Trabalho (OIT), tais como aquelas relativas 
ao direito de associação e à liberdade de negociação coletiva. O primeiro AMI foi assinado em 1988, entre a UITA ${ }^{1}$ e a empresa Danone, mas a vasta maioria dos cerca de 120 acordos-marco existentes foi assinada a partir de 2002 (OIT, 2016).

Mais especificamente, este artigo busca evidenciar como esse instrumento pode contribuir para a regulação social das empresas multinacionais e garantir a defesa dos direitos dos trabalhadores em âmbito internacional. Para tanto, ele se divide em três partes. Na primeira, após uma breve retomada do surgimento dos AMIs como resposta sindical ao movimento da RSE, aborda os principais efeitos potenciais dos AMIs. Na segunda parte, busca ilustrar suas consequências concretas a partir do estudo de duas multinacionais norte-americanas signatárias de tais acordos. A última parte do artigo permitirá, à luz desses estudos de caso, esclarecer as condições de efetividade e os limites desses AMIs como instrumentos de defesa dos direitos dos assalariados.

\section{Os AMIs como resposta sindical ao movimento de responsabilidade social das empresas}

Assistimos atualmente a uma multiplicação e a uma diversificação das fontes e dos instrumentos de regulação social no plano supranacional. Às organizações intergovernamentais, tais como OIT e ONU, produtoras de normas mais convencionais, associa-se, hoje em dia, um número crescente de atores privados que também querem aproveitar o movimento de responsabilização social da empresa (RSE) e se posicionar como referência nessa questão. Quer se pense no padrão de responsabilidade social SA 8000, concebido no final dos anos 1990 pela Social Accountability International (SAI), no Global Reporting Initiative, ou na elaboração

\footnotetext{
1 UITA - União Internacional dos Trabalhadores da Alimentação e Agricultura.
} 
mais recente da norma ISO 26.000, é grande a tendência à multiplicação dos instrumentos em matéria de RSE (Daugareilh, 2010). Isso levanta, de passagem, interrogações importantes sobre a utilidade dessa diversidade de instrumentos ou ainda sobre a legitimidade do movimento de normalização privada da responsabilidade social (Barrientos; Smith, 2007). Para muitos, o fenômeno de privatização do direito internacional do trabalho e dos instrumentos de RSE se acelerou a partir do início dos anos 1990, após diferentes escândalos corporativos que evidenciaram um déficit de regulação da empresa em nível internacional (Drouin; Duplessis, 2009). A necessidade de preencher esse vazio teria dado origem a uma grande quantidade de códigos de condutas e outras cartas éticas cujos limites já foram amplamente demonstrados e discutidos, principalmente em termos de contribuição à regulação do trabalho nas empresas (Egels-Zandén; Merk, 2014; Locke, 2013).

Diante dessa diversificação de instrumentos de RSE, a maioria das organizações sindicais se contentou, inicialmente, em comentar com desconfiança a evolução em andamento e criticar o alcance dos códigos de conduta, cuja iniciativa parte apenas das direções das empresas. Todavia, algumas organizações procuraram intervir de imediato e de modo mais direto nesse novo terreno de intervenção social constituído pela RSE (Dawkins, 2010). Desse modo, organizações sindicais regionais, nacionais e internacionais se apropriaram gradualmente dessa questão, com posicionamentos e graus de envolvimento variáveis, e começaram a refletir tanto sobre o espaço de regulação constituído pela empresa transnacional quanto sobre a capacidade de essas organizações defenderem os interesses dos trabalhadores (Bourque, 2008). Essa reflexão não só modificou os discursos de várias delas, como os da Confederação Europeia dos Sindicatos (CES) ou os da nova Confederação Sindical Internacional (CSI) que recentemente fez da RSE um de seus campos de intervenção política 
(Hennebert; Bourque, 2010), mas também suscitou o surgimento de novos instrumentos de regulação e de novas vias de ação. A esse respeito, as duas últimas décadas vêm acompanhando a multiplicação de experiências de colaboração intersindical no plano supranacional, visando a encorajar, e até a forçar, as grandes empresas a assumirem verdadeiramente suas responsabilidades sociais (Brookes, 2013; Croucher; Cotton, 2009). O aumento considerável do número de pesquisas sobre as práticas sindicais internacionais (ou labour transnationalism²), tanto nas empresas multinacionais norte-americanas quanto nas europeias (Greer; Hauptmeier, 2008), atesta amplamente essa realidade.

No contexto desse novo ativismo sindical internacional, o dispositivo frequentemente considerado mais avançado para dar um verdadeiro conteúdo à RSE consiste na negociação e assinatura de acordos-marco, defendidos principalmente pelas FSIs nos últimos anos. Ainda que os AMIs tenham suscitado, em seu surgimento, um interesse limitado, observa-se, nos últimos anos, um aumento considerável do número de estudos sobre esse instrumento de regulação das firmas multinacionais (Helfen; Sydow, 2013; Fichter et al., 2011). As primeiras pesquisas sobre os AMIs tinham o objetivo de desmistificá-los, centrando a análise, de início, em seu conteúdo (Bourque, 2005) e, depois, analisando mais especificamente seus impactos potenciais sobre a regulação social das multinacionais e sua contribuição à modelação de um regime internacional de relações industriais (Papadakis, 2011).

\footnotetext{
2 Para Anner, o 'labour transnationalism' pode ser definido como um conjunto de "ações coordenadas por organizações de trabalhadores em pelo menos dois países, direcionadas a atores internacionais, tais como empresas multinacionais" (2007, p. 67). Greer e Hauptmeier vão na mesma linha e definem o conceito da seguinte maneira: "extensão espacial do sindicalismo, através da intensificação da cooperação entre sindicalistas de vários países, por meio de estruturas e instrumentos transnacionais" (2008, p. 77).
} 
Inicialmente, louvou-se o fato de esses acordos serem instrumentos mais impositivos do que os códigos de conduta ou outros instrumentos que repousam em um envolvimento unilateral da parte dos empregadores, e constituírem, assim, um instrumento de RSE muito mais convincente (Egels-Zandén; Hyllmkan, 2007). Wills (2002) relembrou que os AMIs, contrariamente aos códigos de conduta, resultam de uma negociação bilateral entre dirigentes das empresas e representantes sindicais e que implicam certo acompanhamento das partes quanto ao respeito às modalidades constitutivas do acordo. Através de seus mecanismos de operacionalização, esses acordos poderiam propiciar uma ocasião de diálogo e de aprendizagem aos atores patronais e sindicais e, em última instância, de elaboração de soluções comuns para os problemas de respeito aos direitos dos trabalhadores dentro das empresas.

Mais do que um mero instrumento de RSE em meio à variedade existente, muitos viram nesses acordos um instrumento indispensável às organizações sindicais para promover e estender, em diferentes países e níveis, os direitos dos trabalhadores (Schomann et al., 2008). Seguindo essa lógica, devido a seu alcance internacional, os AMIs seriam alavancas importantes para promover tais direitos, principalmente em contextos nacionais onde os ordenamentos jurídicos em matéria de trabalho são pouco desenvolvidos ou ineficazes.

Além disso, embora tenham sido assimilados, quando surgiram, a mecanismos de soft law (normas não vinculantes) (Hepple, 1999), vários observadores matizaram, desde então, essas afirmações, antevendo vias pelas quais esses acordos poderiam desenvolver uma dimensão mais impositiva no plano jurídico (Bercuson; Estlund, 2008). O mesmo se dá atualmente em relação aos debates sobre a recepção das regras prescritas pelos ACls em diferentes sistemas jurídicos nacionais e a possibilidade de processos judiciais contra infrações que atentem aos acordos estabeleci- 
dos nos terceiros países onde uma multinacional esteja instalada (Baylos Grau, 2010). Também foram evocadas outras possibilidades referentes, em especial, à integração desses acordos a outras normas juridicamente impositivas, tais como as convenções coletivas locais ou os contratos das empresas signatárias de AMls com seus fornecedores ou terceirizados (Sobczak, 2007). Nessa ótica, tais acordos contribuiriam, em conjunção com os outros instrumentos de RSE, ao desenvolvimento de um modelo "flexível" de regulação, anunciando, no entanto, um enquadramento regulatório mais institucionalizado e eventualmente mais impositivo em âmbito internacional (Hassel, 2008).

De modo ainda mais fundamental, os AMIs e seu desenvolvimento nos últimos anos teriam contribuído muito para o surgimento de uma nova governança mundial do trabalho e para a instauração de um regime transnacional de relações industriais, em diferentes níveis (Williams et al., 2015; Trubek et al., 2000). Primeiramente, proporcionariam novas dinâmicas de regulação do trabalho, tornando operante um novo espaço de diálogo social e de ação sindical no plano supranacional. Em seguida, legitimariam o papel dos novos atores, particularmente o das FSIs. De fato, a assinatura de um AMIs, independentemente do alcance estruturante de seu conteúdo, implica que as empresas signatárias reconhecem as FSIs como parceiros legítimos das relações de trabalho no plano transnacional. Por fim, esses acordos engendrariam dinâmicas variadas de trocas entre atores sindicais, fora do quadro nacional em que essas interações com frequência se acantonaram. As trocas entre atores sindicais locais, nacionais e internacionais, no decorrer da negociação ou do acompanhamento dos AMls, possibilitariam, desse modo, a criação de uma dinâmica interativa entre territórios, favorecendo a emergência de novas parcerias e de novas possibilidades de ação em múltiplos níveis. Consequentemente, essas trocas contribuiriam para a constituição de um novo regime transnacional 
de relações industriais, no qual a ideia de uma mera oposição entre atores nacionais e supranacionais se dissiparia em detrimento de modos mais complexos de interações e de concerto entre atores (Jobert, 2008).

\section{As consequências dos AMIs como instrumentos de defesa dos direitos dos trabalhadores: dois casos exemplares}

Como acabamos de ver, os estudos sobre os AMls se concentraram, principalmente, em descrever seus efeitos potenciais. Porém, nos últimos anos, vêm sendo publicados estudos de casos que documentam como os atores locais e nacionais mobilizam tais acordos (Williams et al., 2015; Hennebert; Dufour-Poirier, 2013; Niforou, 2012; Fichter et al., 2011; Robinson, 2011; Gregoratti; Miller, 2010). Essas pesquisas de campo buscam compreender melhor como esses acordos permitem aumentar de fato o poder dos atores sindicais na relação de forças com as grandes empresas e delimitar seus efeitos concretos sobre o respeito aos direitos sindicais.

Nessa mesma perspectiva de pesquisa, relataremos, nas seções seguintes, os efeitos dos AMls em duas multinacionais norte-americanas: Chiquita e Quebecor World. A seleção desses casos se insere em uma lógica de replicação (Yin, 2003), que permitirá esclarecer as condições de efetividade dos AMIs. No plano metodológico, salientamos que os materiais utilizados para a análise do primeiro caso repousam em dados secundários coletados em estudos etnográficos variados, os quais revelam principalmente a maneira como os atores sindicais locais e nacionais se mobilizaram para a elaboração e a operacionalização dos AMIs. No caso da empresa Chiquita, como o AMI está em vigor há mais de dez anos, inúmeros estudos apresentaram uma avaliação do impacto desse acordo (Robinson, 2011; Riisgard; Hammer, 2011; Bananalink, 2008; Eurofound, 2008; Frundt, 2007; Riisgard, 2005). No caso da Quebecor World, 
os dados empíricos foram diretamente coletados pelo autor em cerca de trinta entrevistas semiestruturadas, realizadas com presidentes de seções locais sul-americanas, conselheiros nacionais de centrais sindicais europeias, norte-americanas e sul-americanas, assim como representantes de uma FSI. Apesar da diversidade das funções, todos esses sindicalistas tinham o encargo de representar sua organização sindical no exterior, relatar a situação da empresa em seu país, conciliar estratégias de ação e coordenar a mobilização de seus membros.

Entre as outras fontes de informação mobilizadas, coletamos um extenso material documental constituído de inúmeros documentos corporativos, de vários artigos de imprensa descrevendo a situação financeira dessas duas empresas e também do estado de suas relações de trabalho, de múltiplas publicações sindicais, assim como, no caso de uma delas, das atas das reuniões do comitê de empresa europeu.

\subsection{O caso da empresa Chiquita}

Na virada dos anos 2000, em um contexto marcado por múltiplas denúncias das deploráveis condições de trabalho na indústria bananeira na América Latina (Frundt, 2007), a empresa Chiquita Brands International Inc. $^{3}$ empreendeu as primeiras tratativas em matéria de responsabilidade social. No ano 2000, após a adoção de seu próprio código de conduta, Chiquita adotou uma versão levemente modificada das obrigações da norma SA 8000, elaborada pelo Social Accountability International (SAI), o que levou à certificação posterior de todas as plantações de banana da empresa na América Latina, conforme as grandes linhas dessa norma. Em seguida, a empresa se associou ao Ethical Trade Initiative (ETI) Base Code e se comprometeu a prestar contas de seu desempenho ambiental e social

\footnotetext{
3 A sede da empresa Chiquita fica em Cincinnati nos Estados Unidos e emprega mais de 26 mil trabalhadores, principalmente na América Latina.
} 
em um relatório de responsabilidade social. No entanto, a maior evolução se deu com a assinatura de um AMI entre a direção da empresa e a UITA e a organização sindical COLSIBA (Coordinadora Latinoamericana de sindicatos Bananeros) ${ }^{4}$, em junho de 2001.

Além de ter sido o primeiro AMI assinado por uma empresa com sede social fora da Europa até aquele momento, esse acordo se destaca dos outros por diferentes aspectos. Primeiramente, enquanto a maioria das empresas multinacionais signatárias de um AMI fez acordos em um contexto de abertura ao diálogo social, a direção de Chiquita, por sua vez, ratificou o seu, sobretudo para restaurar a imagem da empresa, maculada por uma campanha pública feita pelas organizações sindicais internacionais e pelas ONGs para denunciar a violação dos direitos sindicais na própria empresa e em alguns de seus fornecedores na América Central e do Sul. O acordo feito entre a UITA e a empresa Chiquita é também um dos únicos a incluir limites geográficos em seu campo de aplicação: restringe-se às plantações de bananas da empresa no continente sul-americano (e não nos Estados Unidos). Em relação ao alcance de seu conteúdo, esse acordo se caracteriza por medidas importantes de aplicação e de acompanhamento, que implicam a formação de um comitê diretor conjunto (Review Committee), que deve se reunir duas vezes ao ano, e para o qual a direção de Chiquita e as organizações sindicais signatárias (IUF e COLSIBA) podem mandar até quatro membros cada uma. Além disso, o acordo inclui um dispositivo que impõe à multinacional garantir que os princípios enunciados no acordo são respeitados por seus fornecedores e terceirizados. Por fim, ele instaura um procedimento de auditoria externa, que recorre a ONGs e a consultorias especializadas, para proceder à ins-

\footnotetext{
${ }^{4}$ COLSIBA é um sindicato regional latino-americano que representa mais de 45 mil trabalhadores, distribuídos em diferentes países: Equador, Colômbia, Costa Rica, Panamá, Nicarágua, Honduras e Guatemala.
} 
peção dos locais de trabalho na empresa e nos terceirizados e enviar um relatório ao comitê diretor (Bourque, 2005).

Foram realizados numerosos estudos sobre os efeitos associados a esse AMI, que vigora há mais de dez anos. O estudo de Riisgard (2005) sobre sua operacionalização, realizado pouco depois de sua ratificação, revelou de início uma primeira falha em sua aplicação ligada à divulgação limitada de seu conteúdo aos trabalhadores da empresa. A autora observava, em especial, que o AMI fora comunicado quase exclusivamente aos trabalhadores de um único sindicato, o que limitava a possibilidade de sua utilização por outros trabalhadores como alavanca em campanhas de sindicalização. Essa divulgação limitada do conteúdo do acordo, que não tem, aliás, nenhuma visibilidade no site internet da empresa, foi igualmente constatada no estudo mais recente de Robinson (2011). No entanto, seu estudo apontou algumas inflexões e ressaltou que a empresa fez campanhas de divulgação nas instalações que ela controla diretamente, afixando informações relativas aos diferentes instrumentos de RSE assinados pela empresa nos painéis previstos para esse fim em espaços dedicados aos funcionários.

Alguns anos após a adoção desse acordo-marco, as pesquisas revelaram uma melhoria das condições de trabalho em comparação com as de outras empresas do mesmo setor e na mesma região. As informações coletadas por Robinson a levaram a concluir que

Ao tratar mais especificamente do tema do AMI, os trabaIhadores declararam que sua situação era visivelmente meIhor do que em outras fazendas da região. Uma das razões era que os trabalhadores podiam consultar o organizador do sindicato local e isso significava que as questões que afetavam várias fazendas eram tratadas de forma mais efetiva (2011, p. 173). 
Após a conclusão desse acordo, também se observou um aumento do número de trabalhadores sindicalizados da empresa, da ordem de 5 mil novos membros na Colômbia e em Honduras. O efeito mais positivo associado à implantação desse AMI incidiu, todavia, na melhoria do diálogo social e das relações de trabalho na empresa. O secretário geral da UITA também afirmou que, desde a assinatura desse acordo, em 2001, as ações empreendidas em conjunto pelas partes signatárias ultrapassaram largamente os procedimentos de auditoria social e de acompanhamento previsto no acordo:

Embora Chiquita ainda venha a tomar decisões que nos trarão problemas e às quais nós e nossos membros faremos justa oposição, nós e a COLSIBA temos conseguido resolver uma série de questões decorrentes dessas decisões em favor de nossos membros [...] também temos visto nossos membros usarem o acordo para ampliar a filiação sindical na empresa e em seus fornecedores em vários casos $^{5}$.

Entretanto, certos atores que atuam no âmbito local avaliaram de modo menos positivo, até mesmo mais crítico, os impactos concretos desse AMI. Após a publicação dos relatórios do UITA e do comitê diretor do acordo, os quais registram problemas em sua aplicação - principalmente no que tange ao respeito aos direitos sindicais por parte dos terceirizados na América Central, e da companhia na Costa Rica -, um representante da organização sindical regional, a COLSIBA, reconheceu as dificuldades de aplicação desse acordo, ressaltando, no entanto, que ele se revelou a melhor maneira de encetar um real diálogo social com a direção da empresa (Robinson, 2011). Já o secretário geral de um sindicato local de empregados da empresa Chiquita, na Costa Rica, foi muito mais severo em sua apreciação:

\footnotetext{
5 International Union of Food and Agricultural Workers - IUF website 26 jun 2006 (Arquivos). Disponível em: http://www.iuf.org/cgi-bin/dbman/db.cgi?db=default\&uid=default\&ID=3573 $\&$ view_records $=1 \& w w=1 \&$ en $=1$
} 
O IFA foi rompido e violado tantas vezes que desejamos rasgá-lo ... na prática, não há liberdade de associação [...] ainda há problemas de riscos sanitários e ocupacionais. Os IFA estão desacreditados aqui na Costa Rica [...] registram-se queixas, mas os auditores sociais e os membros das empresas cometem o erro de fazer entrevistas com os trabalhadores nos escritórios da empresa, isso afeta os trabalhadores, e eles não falam o que de fato ocorre na fazenda (citado em Robinson, 2011, p. 174)

De resto, o balanço da efetividade desse acordo e de seus resultados concretos é comedido. Para Robinson, as evidências sugerem que sua ratificação possibilitou uma melhoria do diálogo social na empresa; vários estudos evidenciaram que Chiquita parece ter honrado quase sempre seus compromissos, sobretudo ao aceitar que seus empregados encontrassem dirigentes sindicais, ou ao encorajar o envolvimento dos sindicatos em processos de resolução de problemas (Robinson, 2011). Mesmo reconhecendo esses efeitos positivos, Riisgard e Hammer (2011) serão mais críticos ao identificar certas falhas em sua aplicação: relataram principalmente o fechamento de certas plantações na Guatemala, sem discussões preliminares com os atores envolvidos, conforme o acordo previa. Os autores também destacaram as transformações sofridas pela cadeia de valor da produção bananeira, que se estrutura agora em torno da passagem para uma cadeia liderada pelos compradores (buyer-driven), e o apelo crescente a terceirizados, assim como os desafios que essas transformações levantam para a efetividade futura desse acordo. 


\subsection{O caso da empresa Quebecor World}

Quebecor World ${ }^{6}$ foi uma indústria gráfica canadense, que encerrou suas atividades abruptamente no final da década de 2000. Desde sua fundação, essa empresa cresceu muito, empregando uma estratégia agressiva de aquisição de outras empresas e seguindo uma lógica de internacionalização de suas atividades. No entanto, devido à perturbação do mercado editorial, à capacidade produtiva excedente do setor e aos problemas relacionados à integração das numerosas empresas adquiridas, essa multinacional deu sinais muito claros de perda de dinamismo desde o início dos anos 2000. A inflexão de seus resultados de exploração provocou a redução de seus custos de operação e a supressão de muitos postos de trabalho. Entre 2000 e 2008, foram suprimidos mais de 15 mil empregos, ou seja, um terço de sua mão de obra mundial.

Foi nesse contexto de reestruturação que ocorreram os primeiros contatos internacionais entre representantes dos trabalhadores da Quebecor World. Desde o início, a FSI que representa os trabalhadores do setor de impressão comercial, a Union Network International (UNI), foi peça central no processo. Constatando os problemas de acesso à sindicalização em certas instalações da empresa e preocupada em responder às inquietações de seus associados, a FSI, e mais particularmente sua divisão setorial UNI Graphique, organizou a partir de 2000 os primeiros encontros internacionais visando a promover contatos entre representantes sindicais de trabalhadores da Quebecor World em todo o mundo. Os problemas recorrentes em matéria de reconhecimento da legitimidade sindical, associados às preocupações de certos representantes sindicais com a saúde e a segurança dos empregados nas instalações da empresa, fortaleceram

\footnotetext{
${ }^{6}$ Quebecor World Inc. foi uma das maiores gráficas comerciais do mundo e tinha, no início de 2008, aproximadamente 28 mil empregados ativos em uma rede de mais de 115 gráficas e oficinas de serviços afins em 17 países distribuídos essencialmente em dois continentes (América do Norte e do Sul e Europa).
} 
o desejo de uma base de acordo mais regular. Novos encontros entre delegados sindicais foram organizados e permitiram oficializar um grupo de trabalho batizado de Réseau UNI@Quebecor World ${ }^{7}$ e estabelecer certos objetivos, como o de ampliar o espectro da representação sindical dentro da empresa, dando prioridade estratégica à organização de campanhas de sindicalização (Tate, 2006).

O ano de 2003 foi um ano chave na evolução da rede. Um grande encontro entre seus membros ocorreu de 5 a 10 de dezembro em Memphis, no Tennessee. Nessa "Conferência mundial de solidariedade à Quebecor", mais de 120 delegados sindicais e trabalhadores da empresa, de 14 países diferentes, reuniram-se para discutir os problemas encontrados em seus ambientes respectivos de trabalho. Todavia, o momento forte dessa conferência girou em torno da decisão dos delegados de levar a direção da Quebecor a ratificar um acordo de alcance internacional relativo ao reconhecimento dos direitos sociais e sindicais dos trabalhadores do grupo. Para tanto, as diferentes organizações sindicais presentes decidiram diversificar as estratégias e os meios de ação utilizados para aumentar a pressão sobre a empresa em escala nacional, regional e mundial. Essa decisão culminou com o lançamento de uma campanha internacional de mobilização, batizada de Justice@Quebecor ${ }^{8}$, que reuniu várias ações internacionais organizadas pelos diferentes sindicatos afiliados (Hennebert, 2010).

\footnotetext{
${ }^{7}$ Rede UNI-Quebecor.

8 Nessa campanha sindical internacional, organizaram-se "jornadas mundiais de solidariedade", nas quais os trabalhadores da Quebecor World de diferentes países usaram camisetas com o slogan da campanha, assinaram petições e distribuíram panfletos reivindicando o direito à sindicalização, e, em certos casos, organizaram reuniões em seus ambientes de trabalho. As reivindicações da Rede se estenderam, na sequência, à esfera pública e política graças a diferentes eventos midiáticos. Além da participação de delegações sindicais internacionais em assembleias de acionistas da empresa, empreenderam-se ações para pressionar clientes importantes e sensibilizá-los às reivindicações sindicais. Certas organizações sindicais nacionais recorreram à Justiça para denunciar as práticas da empresa consideradas antissindicais e discriminatórias. Por fim, apelou-se igualmente para as estruturas europeias de diálogo, sobretudo por meio da inclusão de uma discussão sobre os AMIs na pauta de uma reunião do CEE da Quebecor World em 2004.
} 
Um dos principais objetivos dessas mobilizações era criar uma força de negociação, ao exercer múltiplas pressões sobre a empresa e atacar sua imagem pública. $\mathrm{O}$ impacto dessa campanha se fez sentir rapidamente, pois, pouco após seu lançamento, a direção da multinacional canadense estabeleceu contato com os dirigentes da Rede e aceitou negociar um AMI. Essas discussões preliminares levaram finalmente a um processo de negociação que durou cerca de quatro anos ${ }^{9}$ e se concluiu por um acordo ratificado em 4 de maio de 2007, em Barcelona, paralelamente a uma reunião do comitê de empresa europeu.

No entanto, pouco tempo depois da ratificação desse acordo-marco, a situação financeira da Quebecor World declinou dramaticamente. As numerosas medidas de reestruturação, assim como as centenas de milhões investidos na modernização de suas instalações, não conseguiram reverter a tendência que já vinha se delineando há alguns anos e forçaram a empresa a se declarar inadimplente e apelar, em 21 de janeiro de 2008, para a da Lei sobre os arranjos com os credores das companhias do Canadá ${ }^{10^{*}}$.

Contudo, as entrevistas feitas com os representantes sindicais que participaram da negociação do acordo internacional antes do desmantelamento da empresa evidenciaram as múltiplas utilidades desse acordo. Vários sindicalistas insistiram, em primeiro lugar, na importância que esse acordo teve ao criar um projeto comum, uma verdadeira fonte de ação coletiva entre os membros da Rede UNI-Quebecor. Um dirigente sindical canadense do alto escalão explicou:

Eu diria que os sindicatos têm, por vezes, objetivos muito diferentes. [...] O que uniu todos foi este acordo global e, portanto, para mim, minha opinião é que o acordo global foi um instrumento muito útil para manter essa rede unida. Então, não foi uma campanha para ajudar os trabalhado-

9 Bourque e Hennebert (2011) realizaram uma análise detalhada do processo de negociação que levou à assinatura desse AMI.

10 * (N.T.) Lei federal canadense que autoriza as empresas insolventes que devem mais de cinco milhões de dólares a seus credores a reestruturarem seus negócios e finanças. 
res dos Estados Unidos a organizarem um sindicato, não foi uma campanha para manter aberta a fábrica no Reino Unido, não foi uma campanha para organizar os trabalhadores brasileiros. Foi uma campanha para que a empresa assinasse um acordo global. Para reconhecer o direito de organização e, assim, todos puderam sentar-se à mesa e acordar isso.

Outros representantes enfatizaram a importância de contar com uma rede de associados para conseguir os apoios necessários e estabelecer uma relação de forças, que se revelou indispensável à conclusão desse processo de negociação internacional. Um responsável da UNI, diretamente envolvido no processo de negociação, fez a seguinte comparação:

Tivemos outros acordos em que fomos para a empresa, e o presidente dizia "Ótimo, boa ideia, ponha no papel e assinarei" [...] mas ninguém mais se envolvia. Então, nada acontecia depois. Enquanto que, quando isso é combinado com este tipo de campanha, com a mobilização de pessoas da base, significa que, uma vez que o acordo esteja em vigor, eles estarão prontos para fazer valer. E é por isso que esse negócio com a Quebecor tem sido um dos mais interessantes.

Finalmente, muitos representantes sindicais destacaram o fato de que as ações internacionais organizadas no âmbito do processo de negociação desse AMI desempenharam um papel crucial na sindicalização de vários estabelecimentos da empresa, situados principalmente em Recife, Santiago do Chile e Lima, no Peru. Um sindicalista americano declarou:

Para mim, uma das coisas fascinantes dessa campanha foi que ela produziu resultados reais nos EUA. Há trabalhadores hoje, em Kentucky, que têm um sindicato que antes não tinham, por causa desta campanha. E há trabalhadores hoje no Chile, no Brasil e no Peru que antes não tinham. Então, sabe..., a questão não é só: os trabalhadores aqui podem ajudar os americanos? Foi na verdade: como nos reunimos para ajudar todos? E houve resultados reais em vários países, como consequência disso. 


\section{Conclusão: as alianças sindicais internacionais como base social dos AMIs}

Os dois casos aqui apresentados são singulares em vários aspectos. Por um lado, trata-se de duas empresas com sede social na América do Norte. Só esse dado já Ihes confere um aspecto original, visto que os AMIs são geralmente vistos como representantes de uma visão europeia de regulação da empresa globalizada. Por outro lado, em ambos os casos, os acordos internacionais foram assinados após campanhas de mobilização que pressionaram as direções dessas empresas. Mais uma vez, esse elemento se mostra original na medida em que a grande maioria dos AMIs foi assinada em um contexto mais favorável ao diálogo social. Embora essas particularidades demandem certa prudência na generalização das conclusões, elas fornecem informações importantes sobre a efetividade dos acordos enquanto instrumento de RSE.

Em primeiro lugar, os casos analisados indicam que várias "potencialidades" tradicionalmente associadas aos AMIs se verificam na prática e que esses acordos podem ser, de fato, um instrumento útil para os atores sindicais que buscam instituir mecanismos de controle dentro das multinacionais. No caso da empresa Chiquita, a assinatura do acordo contribuiu claramente para a criação de um clima de relações de trabalho mais propícias ao diálogo e às trocas entre representantes patronais e sindicais em diferentes níveis. Em ambos os casos, o acordo foi igualmente utilizado para promover os direitos sindicais em diferentes países. Dentro do grupo Chiquita, as observações de campo feitas após a ratificação do AMI permitiram identificar um aumento do número de trabalhadores sindicalizados nas plantações da empresa. O acordo assinado com a direção da Quebecor World também foi mobilizado na sindicalização de vários estabelecimentos da empresa na América Latina. Tais casos mostram, assim, que os acordos podem representar meios importantes para proteger e 
ampliar os direitos sindicais, principalmente em contextos nacionais cujos ordenamentos jurídicos não favorecem a concretização de tais direitos.

Em segundo lugar, esses casos ilustram o papel desses acordos para impulsionar a ação sindical internacional. Definindo um objetivo comum a ser compartilhado pelo conjunto das organizações sindicais que representam os trabalhadores de uma mesma multinacional, a assinatura de um AMI pode criar um projeto agregador que facilite o desenvolvimento de alianças sindicais e de ações coletivas no plano internacional. Sobre isso, o presidente da Rede UNI-Quebecor defendia que, a priori, o conteúdo normativo do acordo era secundário para ele, se comparado às novas relações de solidariedade entre associados construídas durante o processo de negociação. No caso dessa empresa canadense, o AMI foi essencialmente utilizado de maneira instrumental pelos membros da rede, para criar uma base comum de reivindicações necessária à construção de um contrapoder sindical transnacional e ao reconhecimento de um status ao coletivo formado pelos assalariados. Esse caso também revela o papel de catalisador de um acordo internacional, que cria uma oportunidade para os atores sindicais se aliarem em torno de um objetivo comum, que dá uma meta e um sentido concreto à ação sindical internacional.

O quadro não estaria completo, entretanto, se não indicasse os limites desses dois casos em relação à definição do campo de aplicação dos AMIs. Os estudos sobre esses acordos revelam, em geral, que os representantes sindicais nacionais e internacionais, assim como os administradores que gravitam "no centro" na multinacional em questão, são os que estão mais informados e envolvidos na negociação e na operacionalização dos acordos. Contudo, a história parece diferente nas redes de terceirizados e de fornecedores das empresas signatárias de AMIs ou entre os administradores de certos estabelecimentos e representantes de sindicatos locais, sobretudo quando estes trabalham em um país distante do país-sede da 
multinacional ou em um ambiente institucional hostil à representação coletiva. Os dois casos que estudamos confirmam essa constatação: no caso da Quebecor World, vários sindicatos locais situados nos estados do sul dos Estados Unidos e na América Latina não foram informados da existência do AMI, e problemas importantes de aplicação do acordo também foram observados em certas instalações sul-americanas do grupo Chiquita.

Esse limite referente ao campo de aplicação desses acordos internacionais confirma a especial importância do papel do agente sindical para que esses acordos se tornem e permaneçam um instrumento efetivo de RSE. Na ausência de um ordenamento jurídico mundial que atribua força de direito aos AMIs, e até postule uma inclusão generalizada desses acordos nos ordenamentos nacionais, a efetividade e a perenidade de tal instrumento de RSE não poderão ser garantidas sem que atores sindicais aliados no plano internacional ou regional venham apoiar seu desenvolvimento, acompanhar sua aplicação e garantir uma ressonância social, principalmente local, ao conteúdo dos acordos negociados. A questão da efetividade dos AMIs lança, assim, um desafio particular ao sindicalismo, isto é, aprender a se estruturar eficazmente no nível transnacional a fim de facilitar a troca de informações entre organizações sindicais e, se for o caso, desenvolver estratégias comuns de ação.

Além disso, mesmo reconhecendo que a apropriação dos AMls pelos sindicalistas condiciona sua aplicação, os dois casos estudados mostram que essa apropriação deve passar pelo desenvolvimento de coalizões e de alianças sindicais internacionais que constituam uma base necessária à efetividade dos acordos. Essas alianças podem ser definidas como coalizões relativamente flexíveis de sindicatos de diferentes países que representem trabalhadores de uma mesma multinacional. Elas objetivam, em geral, garantir e consolidar os direitos sindicais, assim como coordenar as atividades sindicais dos associados, principalmente graças às 
trocas regulares de informações e de experiências, que ocorrem durante encontros internacionais.

No entanto, essas alianças não obedecem a um modelo único de organização e seu modo de funcionamento e de ação pode variar sensivelmente de um caso a outro. A título de exemplo, suas estruturas podem ser mais ou menos formais, reunir atores de diferentes níveis (local, nacional ou internacional), derivar importantes ações coletivas (tais como o lançamento de campanhas corporativas internacionais) ou se limitar exclusivamente à implantação de mecanismos de troca de informações. Estudos recentes que buscam desmistificar o funcionamento dessas alianças também evidenciaram os variados modos de inserção dos sindicatos nacionais nesses coletivos internacionais (Hennebert; Dufour-Poirier, 2013; Lévesque; Murray, 2010). De resto, o envolvimento dos sindicatos nacionais pode depender de um conjunto de fatores, tais como a importância atribuída à internacionalização da representação coletiva dos trabalhadores, no plano político, e aos recursos disponíveis e necessários a tal envolvimento. Assim, pode acontecer que organizações sindicais de países em desenvolvimento se encontrem isoladas nessas alianças, pois seus recursos limitados não thes permitem investir adequadamente as esferas de decisão. Elas correm, portanto, o perigo da instrumentalização de sua participação, criando o que Anner denomina "paradoxo do transnacionalismo sindical" (Anner, 2007).

Por outro lado, mesmo que essas alianças possam se assemelhar a redes sociais, as relações entre os atores que as arquitetam obedecem a certas hierarquias. O caso Quebecor World é emblemático dessa situação. Desde sua formação, a Rede uni-Quebecor formou um verdadeiro comitê diretor com representantes da UNI e de cinco sindicatos nacionais, responsável por organizar e dirigir os encontros regulares entre representantes sindicais. Por outro lado, esse comitê pautou fortemente esses en- 
contros e definiu as regras de envolvimento e de divisão do trabalho que permitiram a implantação de uma importante campanha de mobilização. Em suma, internamente, ele se impôs, como uma verdadeira célula de tomada de decisão e de criação de regras e, no plano transnacional, como um interlocutor legítimo junto à direção da multinacional canadense.

Finalmente, o desenvolvimento desse tipo de aliança necessita contar, sem dúvida, com atores capazes de assegurar um planejamento estratégico e uma coordenação das ações em nível internacional. Muitos duvidaram da capacidade das organizações sindicais internacionais para cumprir semelhante tarefa (Brecher et al., 2006), mas se deve considerar as transformações sofridas por essas organizações nos últimos anos a fim de explorar melhor a força que seu caráter transnacional lhes confere. Mais uma vez, os casos estudados aqui demonstram o papel central das FSIs envolvidas - UITA e UNI -na negociação e na implantação dos AMIs. Ainda que não tenham a autoridade e a legitimidade que a regra de Direito poderia Ihes dar, as FSIs surgem cada vez mais como as estruturas do sindicalismo internacional mais adaptadas às novas realidades econômicas e sociais. Porém, mesmo que se revelem, hoje em dia, uma das "forças imaginativas do direito" (Daugareilh, 2006, p. 116), essas organizações não podem, sozinhas, carregar o fardo da aplicação das novas normas que elas criaram. A esse respeito, o modelo fornecido pelas alianças sindicais internacionais, embora não represente uma panaceia, constitui certamente um modelo pertinente para permitir que as organizações sindicais desenvolvam um verdadeiro contrapoder no seio das multinacionais e assegurar efetividade às novas normas emergentes.

Marc-Antonin Hennebert é PhD em Relações Industriais e Professor no Departamento de Gestão de Recursos Humanos da HEC/Montréal e pesquisador associado do Centre de Recherche Interuniversitaire sur la Mondialisation et le Travail (CRIMT). \Mmarc-antonin.hennebert@hec.ca 


\section{Referências}

1. ANNER, M. Corporate social responsibility and freedom of association rights: The precarious quest for legitimacy and control in global supply chains. Politics \& Society, v. 40, n. 4, p. 609-644, 2012.

2. ANNER, M. The Paradox of Labour Transnationalism: Trade Union Campaigns for Labour Standards in International Institutions. En PHELAN, C., The Future of Organised Labour: Global Perspectives, Oxford, Peter Lang, 2007, pp. 63-90.

3. BARRIENTOS, S.; SMITH, S. Do workers benefit from ethical trade? Assessing codes of labour practice in global production systems. Third World Quarterly, v. 28, n. 4, p. 713-729, 2007.

4. BAYLOS GRAU, A. Nouveaux espaces de règlementation dans la mondialisation: entreprises transnationales et accords-cadres internationaux. En : DAUGAREILH, I. Responsabilité sociale de l'entreprise transnationale et globalisation de l'économie, Bruxelles, Bruylant, 2010, pp. 195-214.

5. BERCUSON, B.; ESTLUND, C. Regulating Labour in the Wake of Globalisation. New Challenges, New Institutions. Oxford and Oregon, Hart Publishing, 2008, 281 p.

6. BOURQUE, R.; HENNEBERT, M-A. Cross-Border Trade Union Action in a Canadian Multinational Corporation. The International Journal of Comparative Labour Law and Industrial Relations, v. 27, n. 3, p. 271-286, 2011.

7. BOURQUE, R. Contribution des codes de conduite et des accords-cadres internationaux à la responsabilité sociale des entreprises. La Revue de I'IRES, v. 57, n. 2, p. 23-53, 2008.

8. BOURQUE, R. Les accords-cadres internationaux $(\mathrm{ACl})$ et la négociation collective internationale à l'ère de la mondialisation. Genève: Organisation internationale du travail, 2005.

9. BRECHER, J.; COSELLO, T.; SMITH, B. International Labor Solidarity: The New Frontier. New Labor Forum, v. 15, n. 1, p. 9-18, 2006.

10. BROOKES, M. Varieties of Power in Transnational Labor Campaigns: Understanding Workers' Structural, Institutional, and Coalitional Power in the Global Economy. Labor Studies Journal, v.38, n. 3, p. 181-200, 2013.

11. CROUCHER, R.; COTTON, E. Global Unions Global Business. Global Union Federations and International Business. London, Middlesex University Press, 2009.

12. DAUGAREILH, I. Responsabilité sociale de l'entreprise transnationale et globalisation de l'économie. Bruxelles, Bruylant, 2010. 
13. DAUGAREILH, I. Les accords-cadres internationaux : une réponse européenne à la mondialisation de l'économie ? En : DESCOLONGES, M. ; SAINCY, B. Les nouveaux enjeux de la négociation sociale internationale, Paris, La Découverte, 2006, pp. 116-129.

14. DEHNEN, V. Transnational Alliances for Negotiating International Framework Agreements: Power Relations and Bargaining Processes between Global Union Federations and European Works Councils. British Journal of Industrial Relations, v. 51, n. 3, p. 577-600, 2013.

15. DROUIN, R-C.; DUPLESSIS, I. La régulation internationale du travail de 1998 à 2008? : un Eldorado normatif ou un désert interprétatif? Lex Electronica, Revue du Centre de recherche en droit public, v. 14, n. 2, p. 1-28, 2009.

16. EGELS-ZANDÉN, N.; HYLLMAN, P. Evaluating strategies for negotiating workers' rights in transnational corporations: the effects of codes of conduct and global agreements on workplace democracy. Journal of Business Ethics, v.76, n. 2, p. 207-223, 2007.

17. EGELS-ZANDÉN, N.; MERK, J. Private Regulation and Trade Union Rights: Why Codes of Conduct Have Limited Impacton Trade Union Rights. Journal of Business Ethics, v. 123, n. 3, p. 461-473, 2014.

18. FICHTER, M.; HELFEN, M.; SYDOW, J. Employment Relations in Global Production Networks: Initiating Transfer of Practices via Union Involvement. Human Relations, v. 64, n. 4, p. 599-622, 2011.

19. FRUNDT, H. J. Unions wrestle with corporate codes of conduct. Working USA, v. 7, n. 4, p. 36-69, 2007.

20. GEREFFI, G.; LEE, J. Economic and social upgrading in global value chains and industrial clusters: Why governance matters. Journal of Business Ethics, v. 133, n. 91, p. 25-38, 2016.

21. GREER, I.; HAUPTMEIER, M. Political Entrepreneurs and Co-Managers: Labour Transnationalism at Four Multinational Auto Companies. British Journal of Industrial Relations, v. 46, n. 1, p.76-97, 2008.

22. GREGORATTI, C.; MILLER, D. International Framework Agreements for Workers' Rights? Insights from River Rich Cambodia. Global Labour Journal, v. 2, n. 2, p. 84-105, 2010.

23. HASSEL, A. The Evolution of a Global Labor Governance Regime. Governance: An International Journal of Policy, Administration, and Institutions, v. 21, n. 2, p. 231-251, 2008.

24. HELFEN, M.; SYDOW, J. Negotiating as institutional work: The case of labour standards and international framework agreements. Organization Studies, v. 34, n. 8, p. 1073-1098, 2013. 
25. HENNEBERT, M-A. Les alliances syndicales internationales, des contrepouvoirs aux entreprises multinationales? Paris, L'Harmattan, Collection Logiques sociales, 2010.

26. HENNEBERT, M-A.; BOURQUE, R. Origines, enjeux et défis actuels de la Confédération syndicale internationale (CSI). Regards sur le travail, v. 7, n. 2, p. 1-11, 2010.

27. HENNEBERT, M-A.; DUFOUR-POIRIER, M. L'action collective au sein des alliances syndicales internationales : deux études de cas contrastées. Relations industrielles/Industrial Relations, v. 68, n. 1, p. 3-24, 2013.

28. HEPPLE, B. A Race to the Top? International Investment Guidelines and Corporate Codes of Conduct. Comparative Labor Law \& Policy Journal, v. 20, n. 3, p. 347-363, 1999.

29. JOBERT, A. Les nouveaux cadres du dialogue social. Europe et territoires. Bruxelles, PIE-Peter Lang, 2008.

30. LÉVESQUE, C.; MURRAY, G. Trade-union cross-border alliances within MNCs: Disentangling union dynamics at the local, national and international levels. Industrial Relations Journal, v. 41, n. 4, p. 312-332, 2010.

31. LOCKE, R. M. The promise and limits of private power: Promoting labor standards in a global economy. New York,Cambridge University Press, 2013.

32. MCCALLUM, J. K. Global unions, local power. The new spirit of transnational labor organizing. Ithaca: Cornell University Press, 2013.

33. MILBERG, W.; WINKLER, D. Outsourcing economics: global value chains in capitalist development. Cambridge, Cambridge University Press, 2013.

34. MURRAY, G. La transnationalisation des modes de production et ses conséquences. En : VERGE, P. Droit international du travail. Perspectives canadiennes, Cowansville, Éditions Yvon Blais, 2010 pp. 5-32.

35. NIFOROU, C. International Framework Agreements and Industrial Relations Governance: Global Rhetoric versus Local Realities. British Journal of Industrial Relations, v. 50, n. 2, p. 352-373, 2012.

36. OIT. Le travail décentdans les chaînes d'approvisionnement mondiales. Conférence internationale du travail, $105^{\mathrm{e}}$ session, Rapport IV, Genève, Organisation internationale du travail, 2016.

37. PAPADAKIS, K. Shaping Global Industrial Relations. The Impact of International Framework Agreements. Genève, OIT, Institut international d'études sociales, 2011. 
38. RIISGARD, L. International Framework Agreements: A New Model for Securing Workers Rights? Industrial Relations, v. 44, n. 4, p. 707-737, 2005.

39. RIISGARD, L.; HAMMER, N. Prospects for Labour in Global Value Chains: Labour Standards in the Cut Flower and Banana Industries. British Journal of Industrial Relations, v. 49, n. 1, p. 168-190, 2011.

40. ROBINSON, P. International Framework Agreements: Do Workers Benefit in a Global Banana Supply Chain? En : PAPADAKIS, K. Shaping Global Industrial Relations. The Impact of International Framework Agreements, Genève, Organisation internationale du travail, 2011.

41. SCHOMANN, I.; SOBCZAK, A.; ECKHARD, V.; WILKE, P. International Framework Agreements: New Paths to Workers' Participation in Multinationals' Governance. Transfer, v. 14, n. 1, p. 111-126, 2008.

42. SOBCZAK, A. Legal Dimensions of International Frameworks Agreements in the Field of Corporate Social Responsibility. Relations industrielles/Industrial relations, v. 62, n. 3, p. 466-491, 2007.

43. TATE, A. The Justice @ Quebecor campaign: Lessons for Canadian Unions. Just Labour, A Canadian Journal of Work and Society, v. 8, p. 40-49, 2006.

44. TRUBEK, D. M.; MOSHER, J.; ROBENSTEIN, J. Transnationalism in the Regulation of Labor Relations: International Regimes and Transnational Advocacy Networks. Law \& Social Inquiry, v. 25, n. 4, p. 1187-1211, 2000.

45. WILLIAMS, G.; DAVIES, S.; CHINGUNO, C. Subcontracting and Labour Standards: Reassessing the Potential of International Framework Agreements. British Journal of Industrial Relations, v. 53, n. 2, p. 181-203, 2015.

46. WILLS, J. Bargaining for the Space to Organize in the Global Economy: a Review of the Accor-IUF Trade Union Rights Agreement. Review of International Political Economy, v. 9, n. 4, p. 675-700, 2002.

47. YIN, R. K. Case Study Research. Design and Methods. London: Sage Publications, 2003, 181 p.

Recebido em: 27.12.2016

Aceite em: 22.03.2017 